\title{
Sensitive Water Probing through Nonlinear Photon Upconversion of Lanthanide-Doped Nanoparticles
}

Shaohong Guo, Xiaoji Xie, ${ }^{*}$ Ling Huang, ${ }^{*}$ and Wei Huang*

Key Laboratory of Flexible Electronics (KLOFE), Institute of Advanced Materials (IAM), Jiangsu National Synergetic Innovation Center for Advanced Materials (SICAM), Nanjing Tech University (NanjingTech), Nanjing 211816, China

Key Laboratory for Organic Electronics and Information Displays, Institute of Advanced Materials, Jiangsu National Synergetic Innovation Center for Advanced Materials (SICAM), Nanjing University of Posts \& Telecommunications, Nanjing 210023, China

*Email: iamxjxie@njtech.edu.cn; iamlhuang@njtech.edu.cn; iamwhuang@njtech.edu.cn. 
(a)

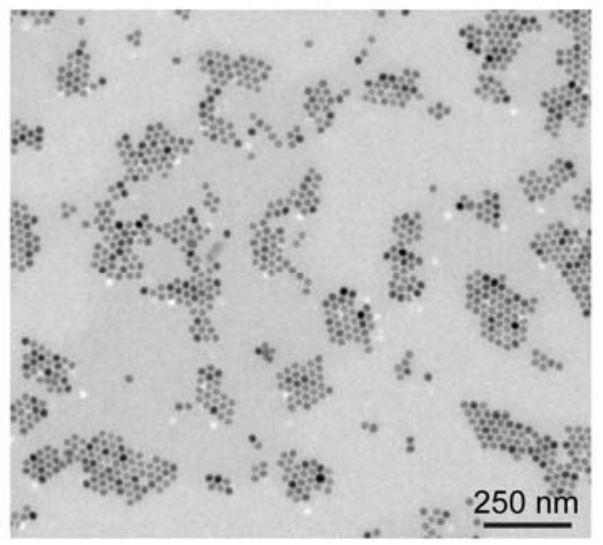

(b)

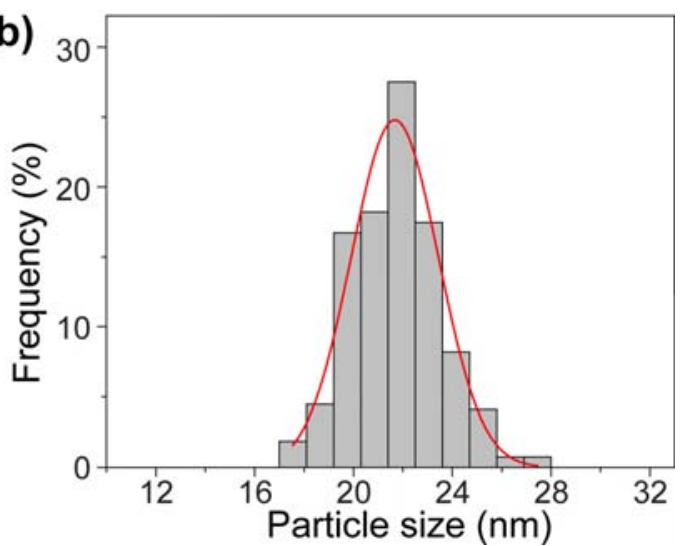

Figure S1. (a) TEM image and (b) corresponding size distribution of the oleic acid capped $\mathrm{NaYF}_{4}: \mathrm{Yb} / \mathrm{Er}(18 / 2 \mathrm{~mol} \%)$ nanoparticles.

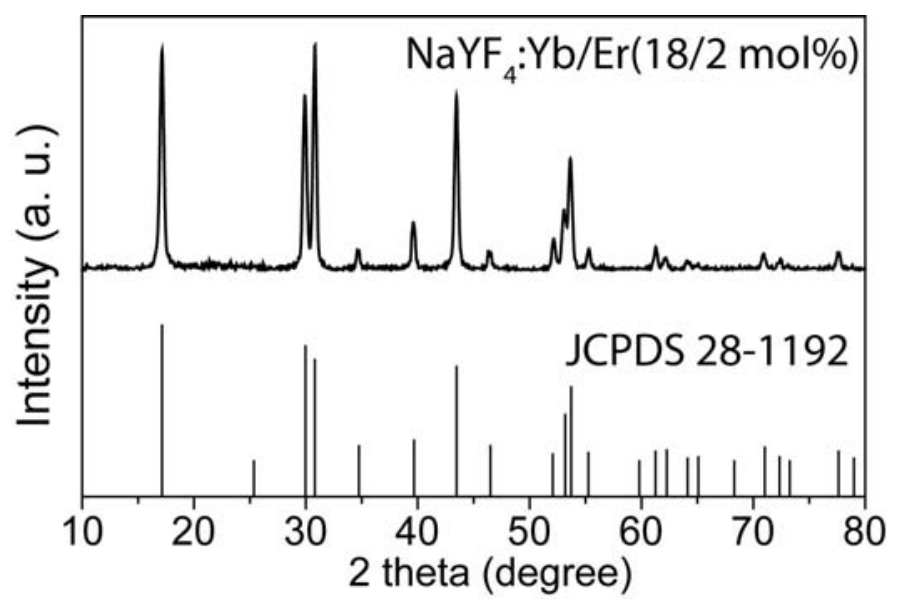

Figure S2. XRD pattern of the as-synthesized $\mathrm{NaYF}_{4}: \mathrm{Yb} / \mathrm{Er}(18 / 2 \mathrm{~mol} \%)$ nanoparticles. The diffraction pattern at the bottom is the literature reference for hexagonal $\mathrm{NaYF}_{4}$ crystal (Joint Committee on Powder Diffraction Standards file number 28-1192). 


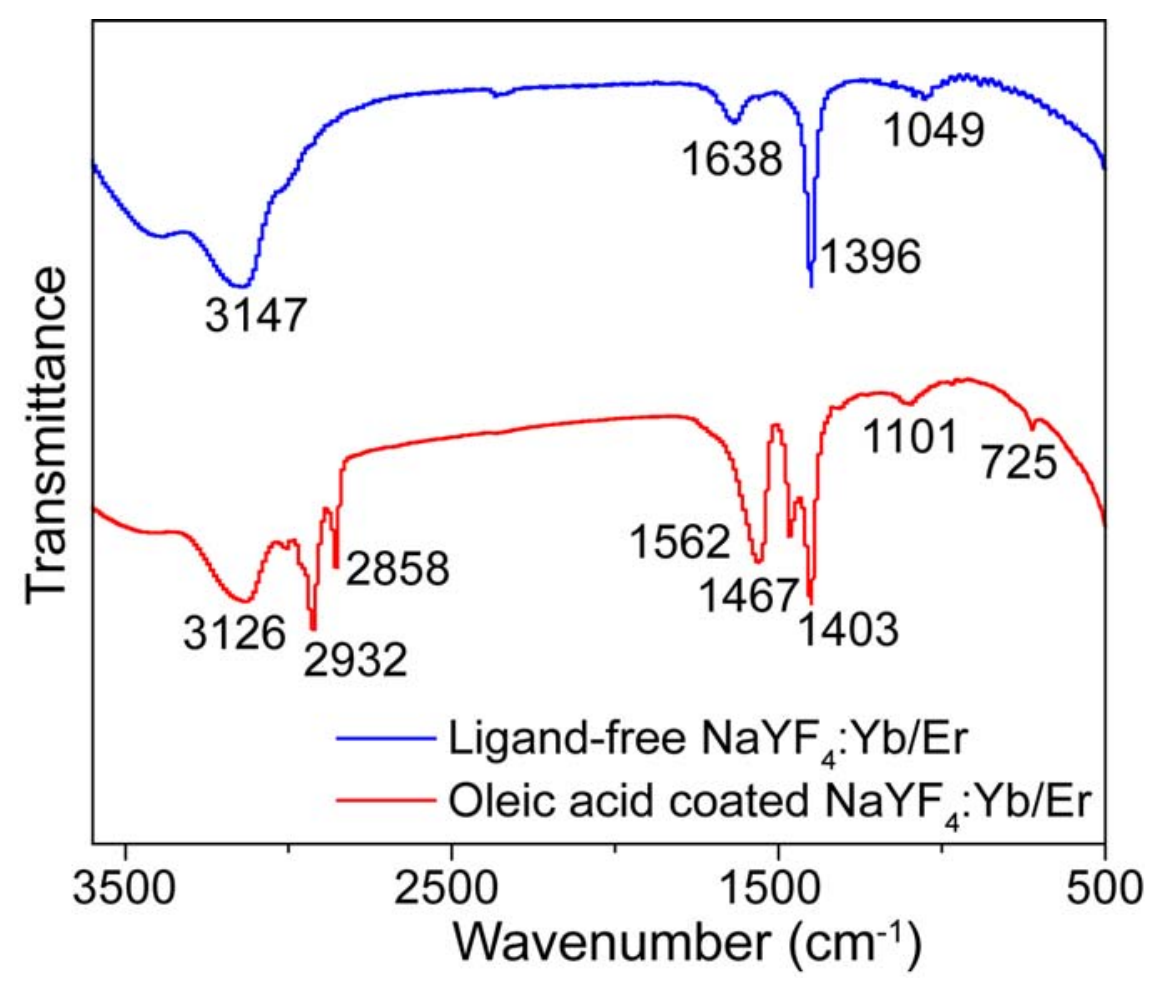

Figure S3. FTIR spectra of oleic acid coated $\mathrm{NaYF}_{4}: \mathrm{Yb} / \mathrm{Er}$ and corresponding ligand-free nanoparticles, respectively. The disappearance of the peaks at 2932, 2858, 1562, and 1467 $\mathrm{cm}^{-1}$ indicates the successful removal of oleic acid. 

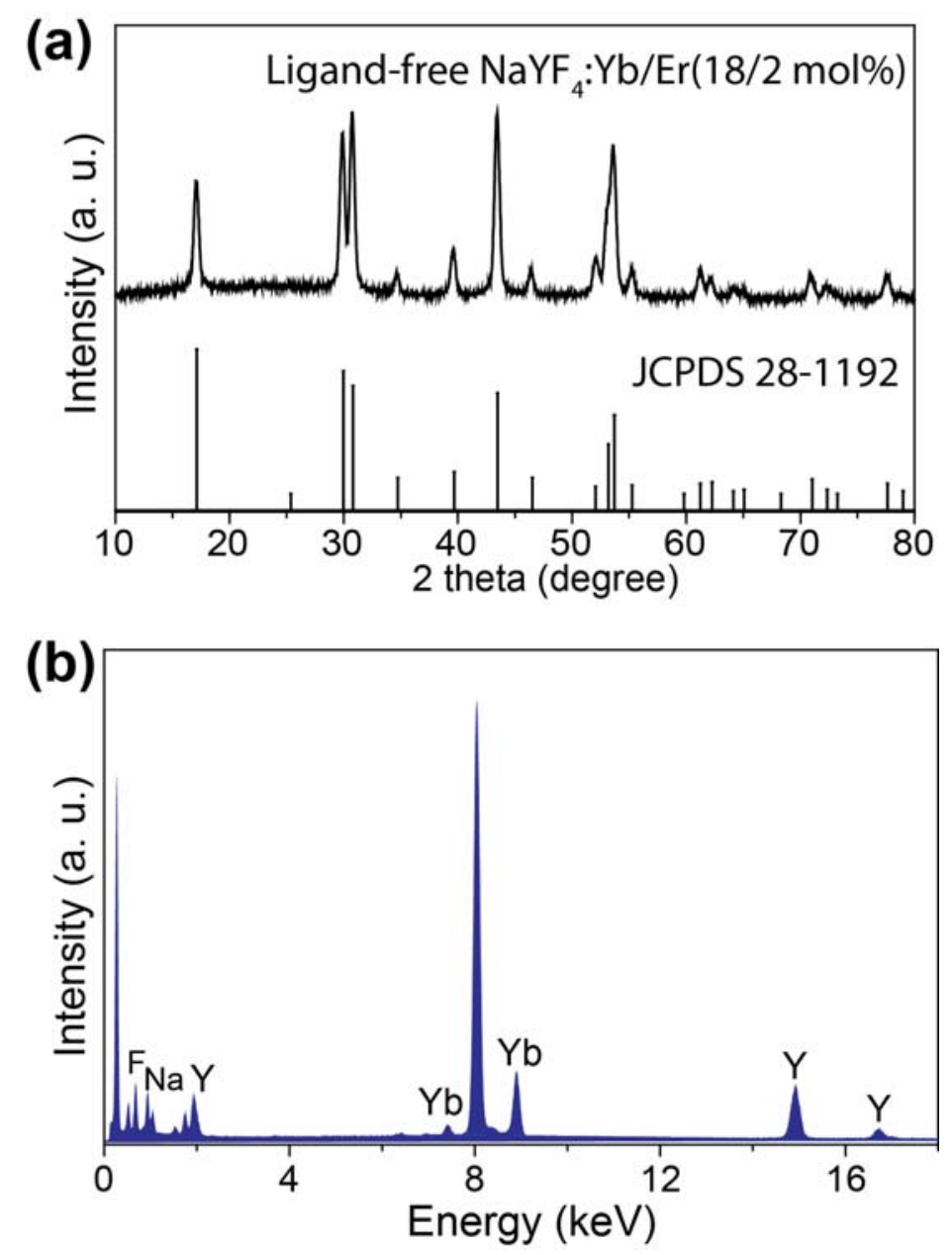

Figure S4. (a) XRD pattern of ligand-free $\mathrm{NaYF}_{4}: \mathrm{Yb} / \mathrm{Er}(18 / 2 \mathrm{~mol} \%)$ nanoparticles. The diffraction pattern at the bottom is the literature reference for hexagonal NaYF4 crystal (Joint Committee on Powder Diffraction Standards file number 28-1192). (b) The energy dispersive $\mathrm{X}$-ray spectrum of the ligand-free $\mathrm{NaYF}_{4}: \mathrm{Yb} / \mathrm{Er}(18 / 2 \mathrm{~mol} \%)$ nanoparticles, indicating the existence of $\mathrm{Na}^{+}, \mathrm{F}^{-}, \mathrm{Y}^{3+}$, and $\mathrm{Yb}^{3+}$. 


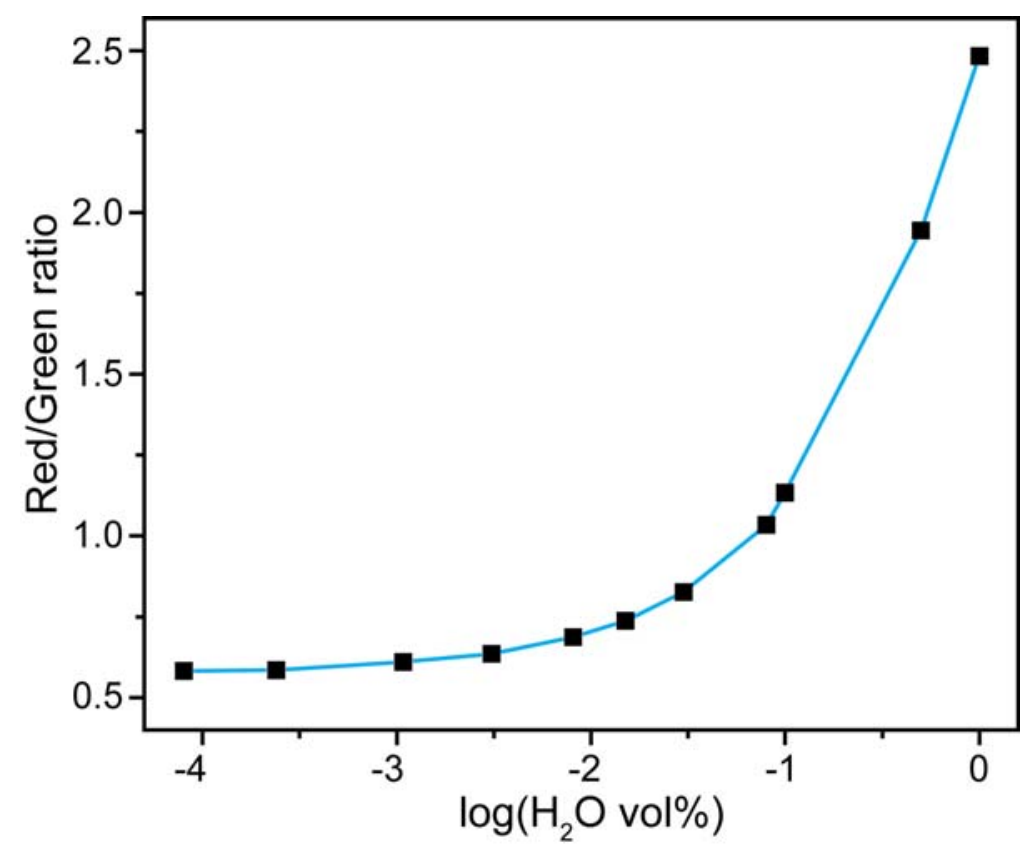

Figure S5. Integrated ratio of red-to-green emission of ligand-free $\mathrm{NaYF}_{4}: \mathrm{Yb} / \mathrm{Er}$ nanoparticles as a function of $\mathrm{H}_{2} \mathrm{O}$ concentration $(0.008-100 \mathrm{vol} \%)$. The concentration of ligand-free nanoparticles was $0.1 \mathrm{mg} / \mathrm{mL}$. Note that the integrated intensity of red and green emission are from the ${ }^{2} \mathrm{H}_{11 / 2}\left({ }^{4} \mathrm{~S}_{3 / 2}\right)$ to ${ }^{4} \mathrm{I}_{15 / 2}$ and ${ }^{4} \mathrm{~F}_{9 / 2}$ to ${ }^{4} \mathrm{I}_{15 / 2}$ transitions, respectively. 

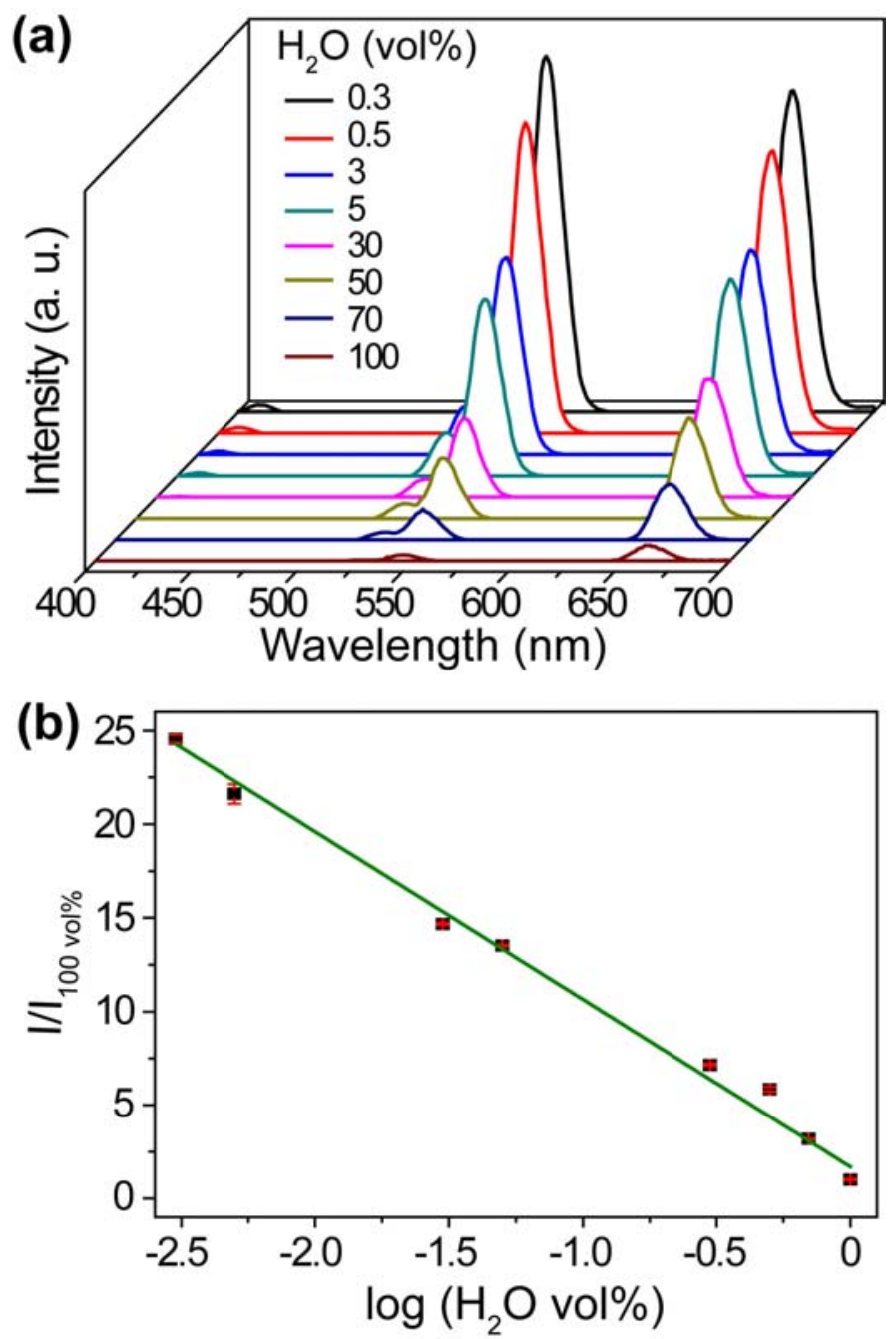

Figure S6. (a) Upconversion emission changes of the redispersed ligand-free $\mathrm{NaYF}_{4}: \mathrm{Yb} / \mathrm{Er}$ nanoparticles as a function of $\mathrm{H}_{2} \mathrm{O}$ concentration (0.3-100 vol \%) in DMF. (b) Corresponding relative emission intensity dependence on $\mathrm{H}_{2} \mathrm{O}$ concentration. Note that the emission intensity was obtained by integrating the emission from 400 to $700 \mathrm{~nm}$. Data are presented as the average from three measurements. 


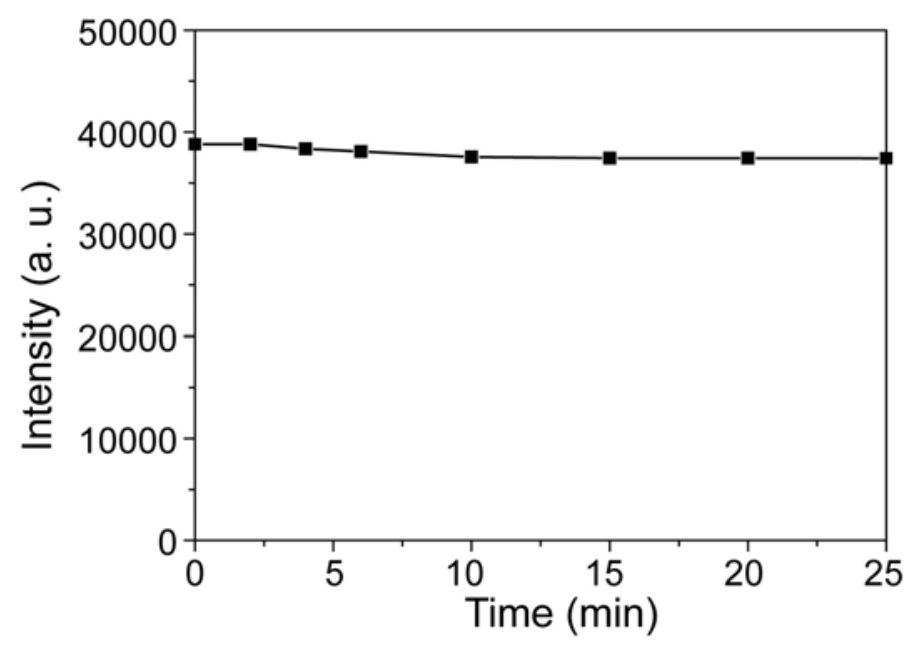

Figure S7. The photoluminescence of ligand-free $\mathrm{NaYF}_{4}: \mathrm{Yb} / \mathrm{Er}$ nanoparticles in $\mathrm{DMF}$ solution containing $10 \mathrm{vol} \%$ of water under continuous excitation ( $980 \mathrm{~nm}$ laser) for $25 \mathrm{~min}$.

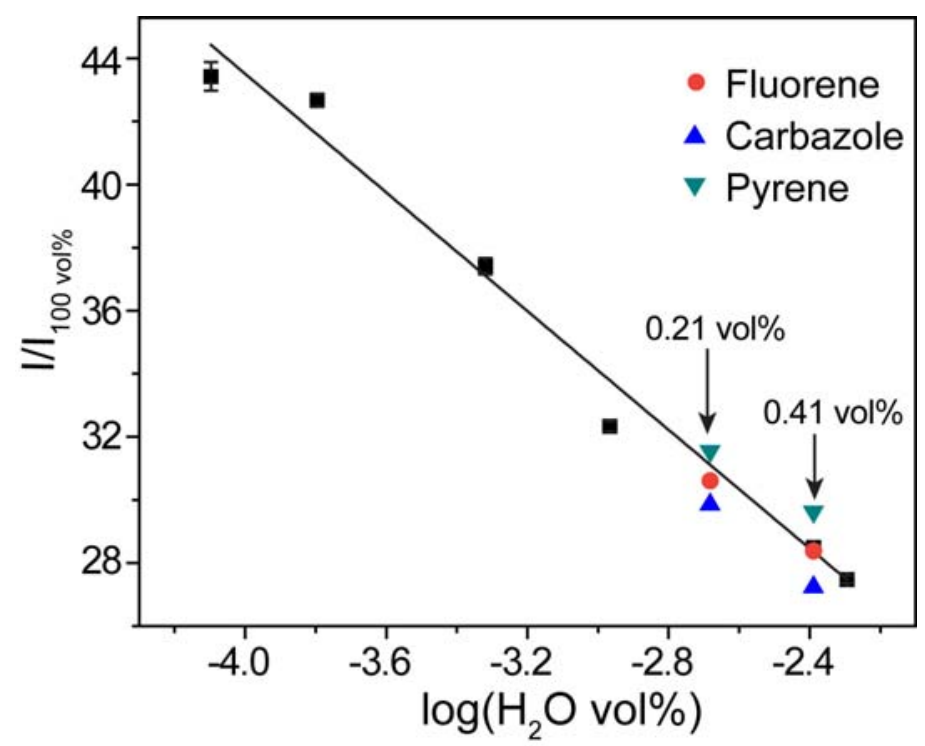

Figure S8. The photoluminescence response of ligand-free $\mathrm{NaYF}_{4}: \mathrm{Yb} / \mathrm{Er}$ upconversion nanoparticles to DMF solution containing organic dye disruptors (Fluorene: $12 \mu \mathrm{M}$, Carbazole: $24 \mu \mathrm{M}$, Pyrene: $10 \mu \mathrm{M})$. Upconversion emission response to DMF containing both $\mathrm{H}_{2} \mathrm{O}(0.21$ and $0.408 \mathrm{vol} \%)$ and organic dyes is almost in line with the calibration curve, indicating small influence of the organic dyes on water probing. 

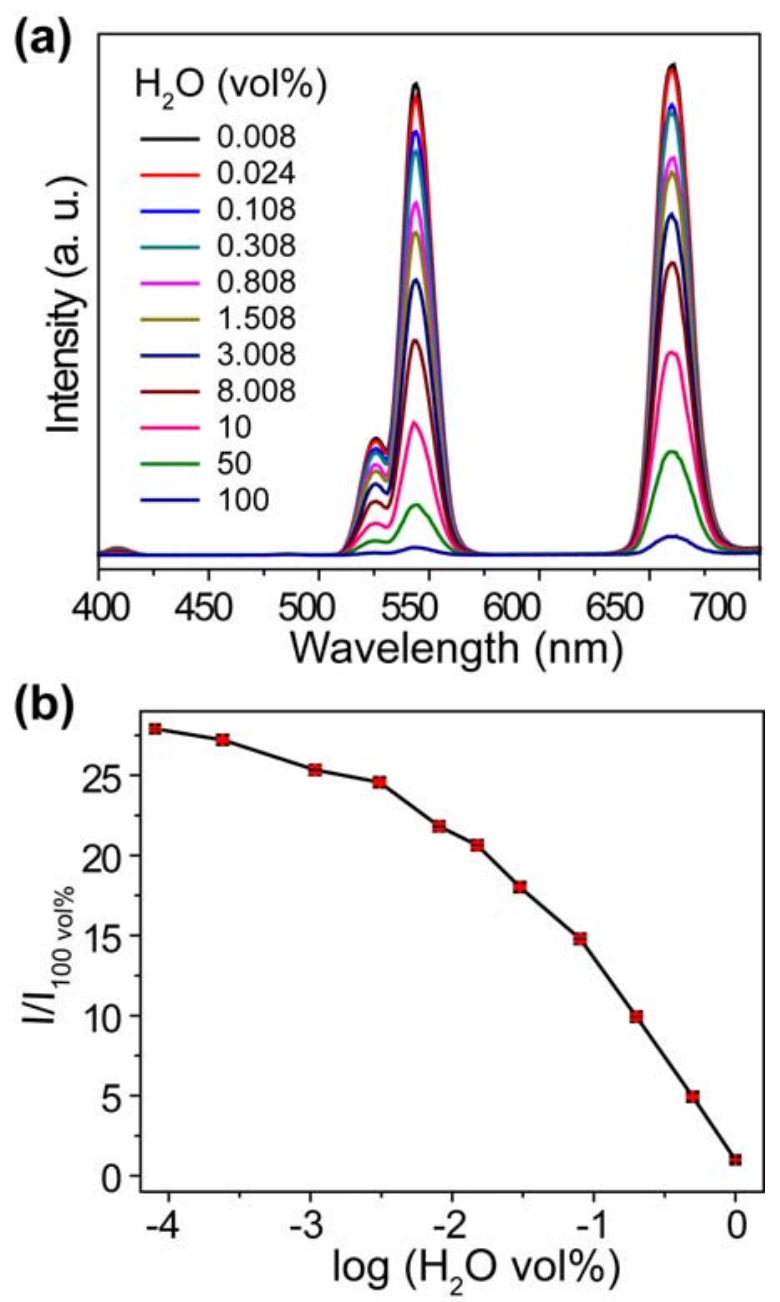

Figure S9. (a) Upconversion emission changes of ligand-free $\mathrm{NaYF}_{4} \mathrm{Yb} / \mathrm{Er}$ nanoparticles as a function of $\mathrm{H}_{2} \mathrm{O}$ concentration (0.008-100 vol \%) in DMSO. (b) Corresponding relative emission intensity dependence on $\mathrm{H}_{2} \mathrm{O}$ concentration. Note that the emission intensity was obtained by integrating the emission from 400 to $700 \mathrm{~nm}$. The line serves as a guide to the eye and data are presented as the average from three measurements. 

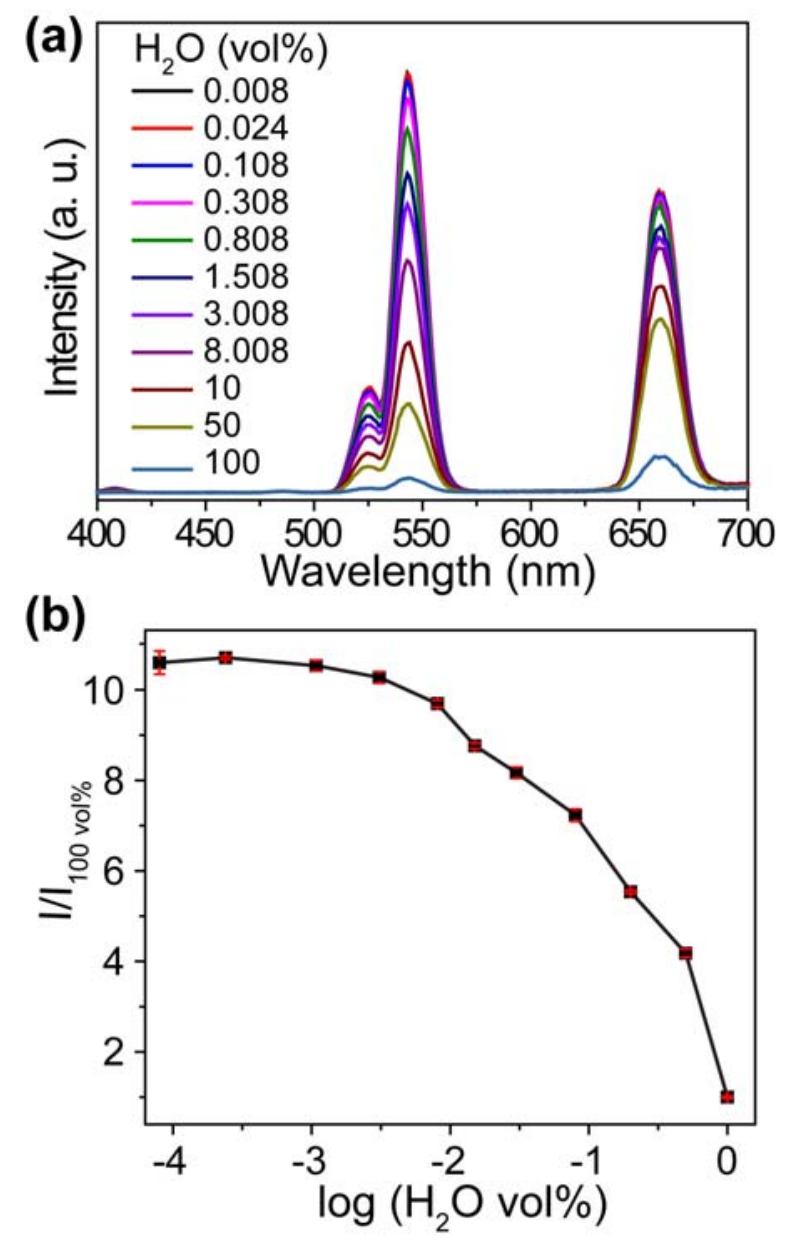

Figure S10. (a) Upconversion emission changes of ligand-free $\mathrm{NaYF}_{4}: \mathrm{Yb} / \mathrm{Er}$ nanoparticles as a function of $\mathrm{H}_{2} \mathrm{O}$ concentration $(0.008-100$ vol \%) in ethanol. (b) Corresponding relative emission intensity dependence on $\mathrm{H}_{2} \mathrm{O}$ concentration. Note that the emission intensity was obtained by integrating the emission from 400 to $700 \mathrm{~nm}$. The line serves as a guide to the eye and data are presented as the average from three measurements. 

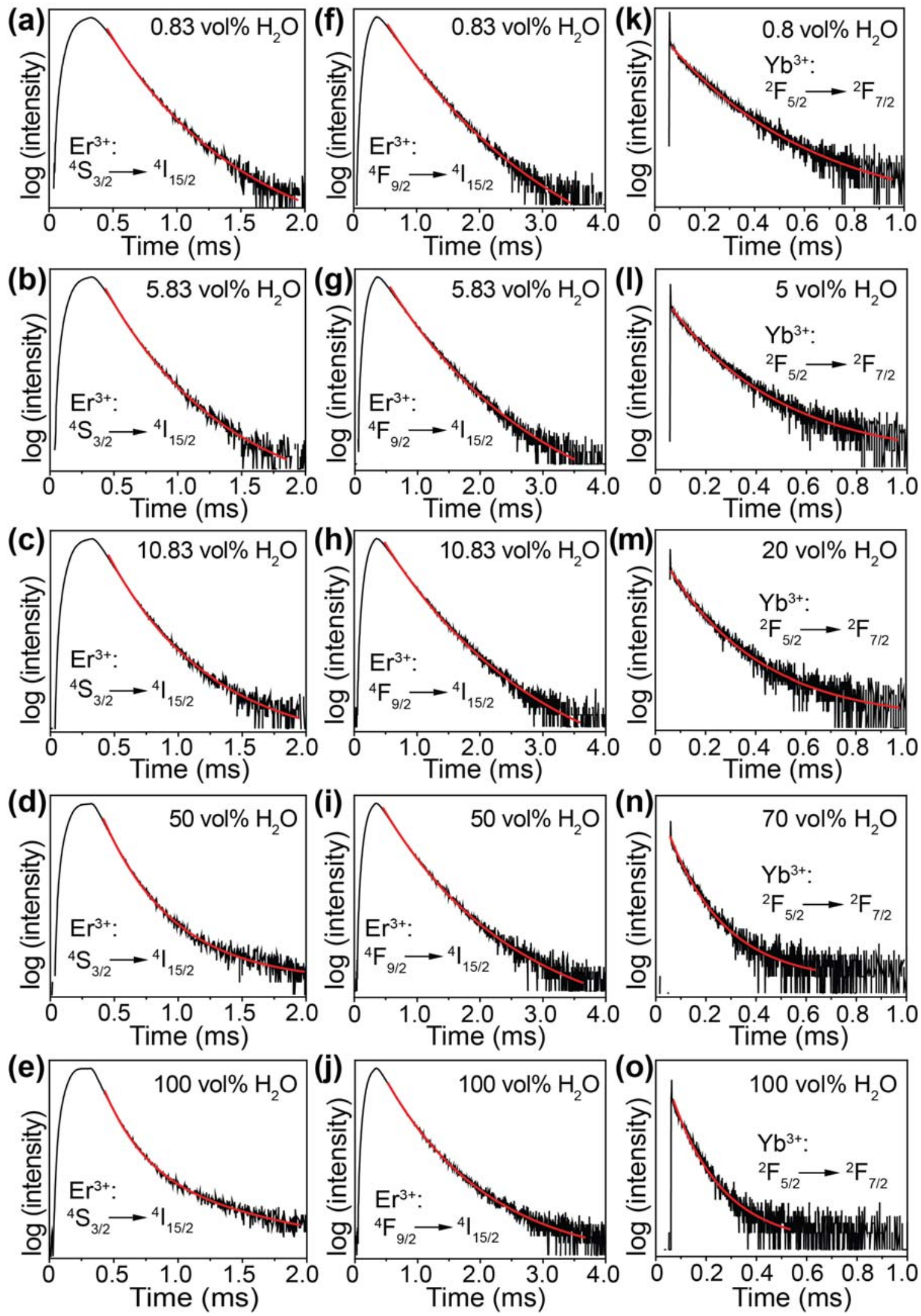

Figure S11. Upconversion luminescence decay curves of ligand-free $\mathrm{NaYF}_{4}: \mathrm{Yb} / \mathrm{Er}$ nanoparticles dispersed in DMF containing varied water content. (a-j) Decay curves of $\mathrm{Er}^{3+}$ measured at (a-e) 540 and (f-j) $654 \mathrm{~nm}$ (excitation: $980 \mathrm{~nm}$ ), respectively. The water 
concentration was $0.83,5.83,10.83,50$ and 100 vol \%, respectively. (k-o) Decay curves of $\mathrm{Yb}^{3+}$ measured at $985 \mathrm{~nm}$ (excitation: $975 \mathrm{~nm}$ ). The water concentration was $0.8,5,20,70$ and 100 vol \%, respectively. Note that the red curve in each profile is the fitting curve.

Table S1. Decay time of $\mathrm{Er}^{3+}$ emission transitions in ligand-free $\mathrm{NaYF}_{4}: \mathrm{Yb} / \mathrm{Er}$ nanoparticles ${ }^{a}$

\begin{tabular}{cll}
\hline $\begin{array}{c}\text { Water content } \\
(\mathrm{vol} \%)\end{array}$ & \multicolumn{1}{c}{$\begin{array}{c}\text { Lifetime of green emission } \\
(\mu \mathrm{s})\end{array}$} & $\begin{array}{c}\text { Lifetime of red emission } \\
(\mu \mathrm{s})\end{array}$ \\
\hline 0.83 & $\tau_{1}: 96(97.6 \%), \tau_{2}: 270(2.4 \%)$ & $\tau_{1}: 200(97.7 \%), \tau_{2}: 960(2.3 \%)$ \\
5.83 & $\tau_{1}: 84(97.1 \%), \tau_{2}: 160(10.9 \%)$ & $\tau_{1}: 190(94.5 \%), \tau_{2}: 480(5.5 \%)$ \\
10.83 & $\tau_{1}: 77(80.3 \%), \tau_{2}: 140(19.7 \%)$ & $\tau_{1}: 190(93.3 \%), \tau_{2}: 420(6.7 \%)$ \\
50 & $\tau_{1}: 69(85.2 \%), \tau_{2}: 150(14.8 \%)$ & $\tau_{1}: 170(83.3 \%), \tau_{2}: 320(16.7 \%)$ \\
100 & $\tau_{1}: 64(84.4 \%), \tau_{2}: 150(15.6 \%)$ & $\tau_{1}: 140(76.3 \%), \tau_{2}: 280(23.7 \%)$ \\
\hline
\end{tabular}

${ }^{a}$ The decay curves were analyzed and fitted by XPFit fitting software.

Table S2. Decay time of $\mathrm{Yb}^{3+}$ emission in ligand-free $\mathrm{NaYF}_{4}: \mathrm{Yb} / \mathrm{Er}$ nanoparticles ${ }^{a}$

\begin{tabular}{cc}
\hline $\begin{array}{c}\text { Water content } \\
(\mathrm{vol} \%)\end{array}$ & $\begin{array}{c}\text { Lifetime of } \mathrm{Yb}^{3+} \\
(\mu \mathrm{s})\end{array}$ \\
\hline 0.8 & 89 \\
5 & 82 \\
20 & 74 \\
70 & 56 \\
100 & 50 \\
\hline
\end{tabular}

${ }^{a}$ The decay curves were analyzed and fitted by XPFit fitting software. 
(a)

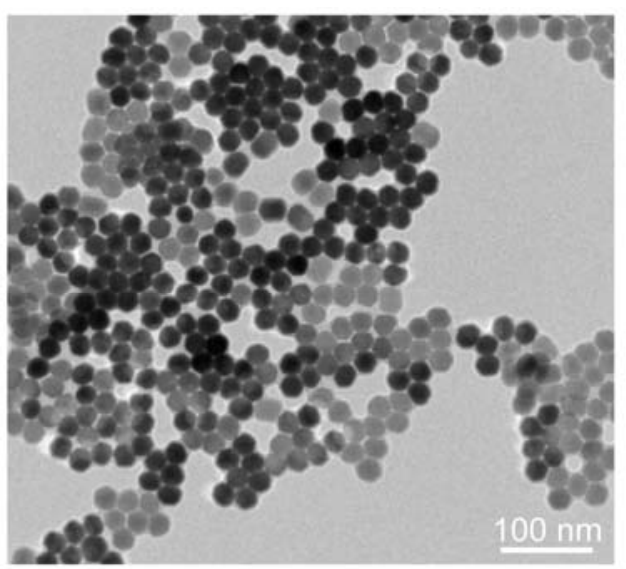

(b)

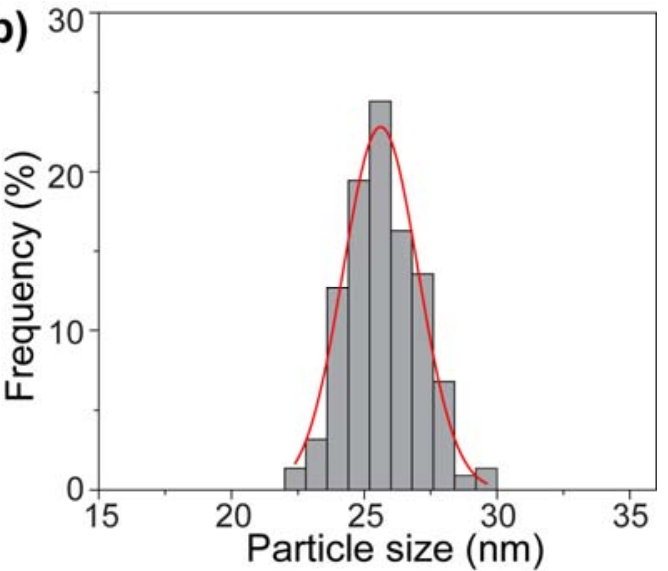

Figure S12. (a) TEM image and (b) corresponding size distribution of the ligand-free $\mathrm{NaYF}_{4}: \mathrm{Yb} / \mathrm{Er}(18 / 2 \mathrm{~mol} \%) @ \mathrm{NaYF}_{4}$ core-shell nanoparticles.

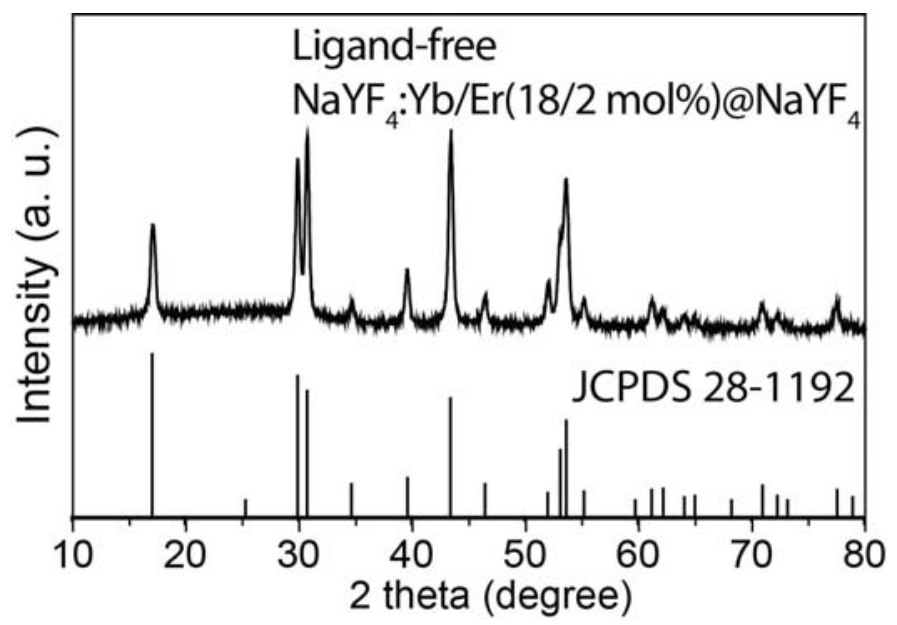

Figure S13. XRD pattern of ligand-free $\mathrm{NaYF}_{4} \mathrm{Yb} / \mathrm{Er}\left(18 / 2\right.$ mol \%)@ $\mathrm{NaYF}_{4}$ core-shell nanoparticles. The diffraction pattern at the bottom is the literature reference for hexagonal $\mathrm{NaYF}_{4}$ crystal (Joint Committee on Powder Diffraction Standards file number 28-1192). 

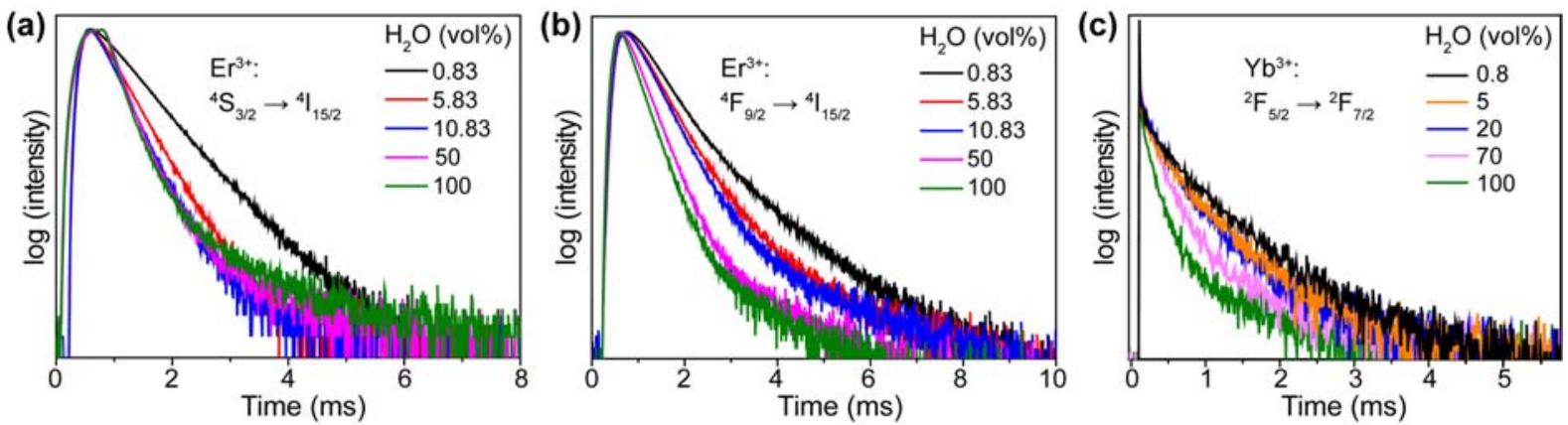

Figure S14. Upconversion luminescence decay curves of ligand-free $\mathrm{NaYF}_{4}: \mathrm{Yb} / \mathrm{Er} @ \mathrm{NaYF}_{4}$ core-shell nanoparticles dispersed in DMF containing varied water contents. $(a, b)$ Decay curves of $\mathrm{Er}^{3+}$ measured at $540 \mathrm{~nm}$ and $654 \mathrm{~nm}$ (excitation: $980 \mathrm{~nm}$ ), respectively. The water concentration was $0.83,5.83,10.83,50$ and 100 vol \%, respectively. (c) Decay curves of $\mathrm{Yb}^{3+}$ measured at $985 \mathrm{~nm}$ (excitation: $975 \mathrm{~nm}$ ). The water concentration was 0.8, 5, 20, 70 and 100 vol \%, respectively. 

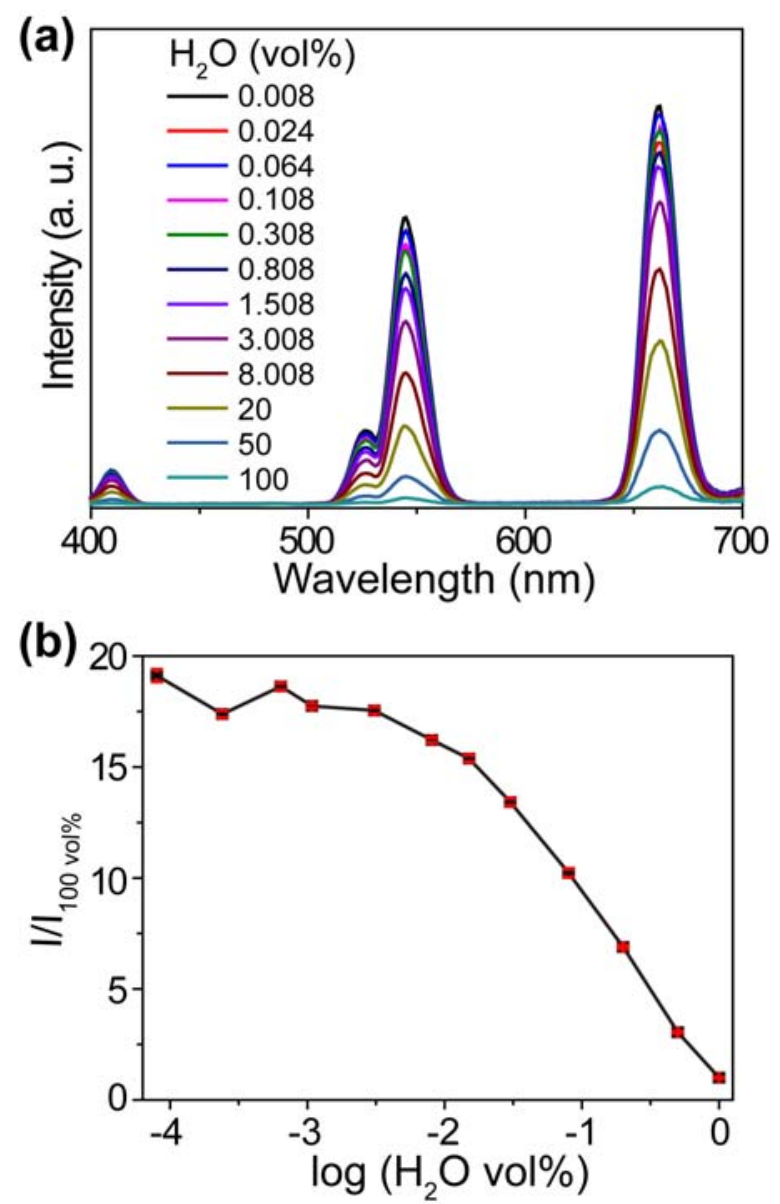

Figure S15. (a) Upconversion emission changes of ligand-free $\mathrm{NaYF}_{4}: \mathrm{Yb} / \mathrm{Er} @ \mathrm{NaYF}_{4}$ core-shell nanoparticles as a function of $\mathrm{H}_{2} \mathrm{O}$ concentration $(0.008-100$ vol \%) in DMF. (b) Corresponding emission intensity dependence on $\mathrm{H}_{2} \mathrm{O}$ concentration. Note that the emission intensity was obtained by integrating the emission from 400 to $700 \mathrm{~nm}$. The line serves as a guide to the eye and data are presented as the average from three measurements. 


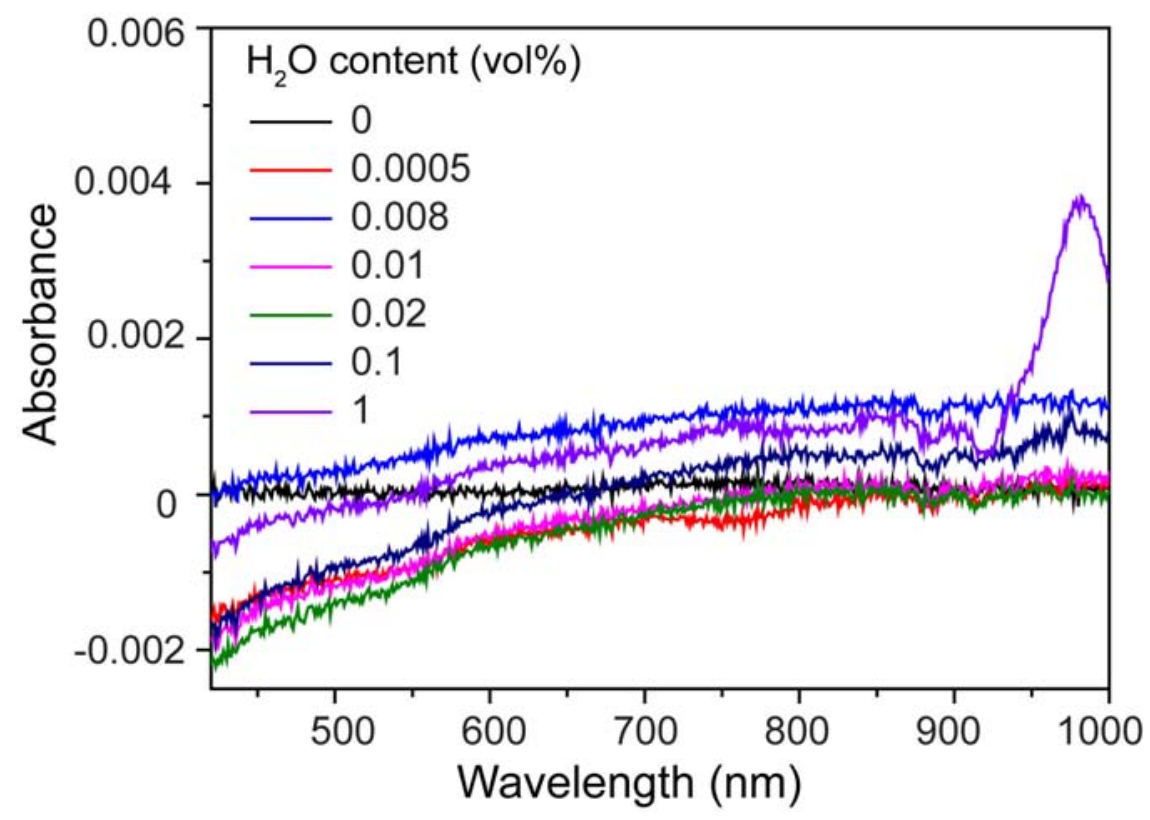

Figure S16. Absorption spectra of DMF containing varied water content (0-1 vol \%). 

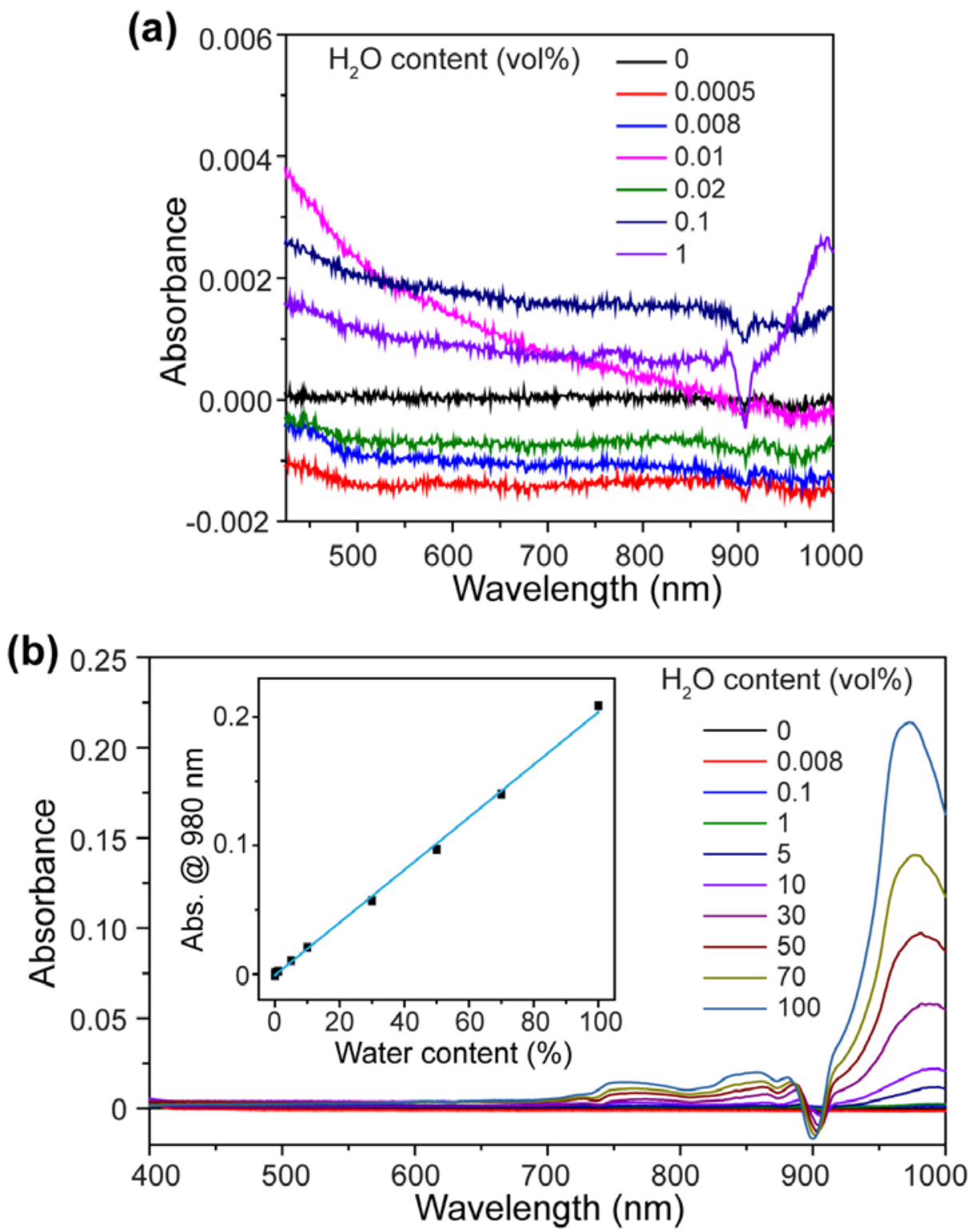

Figure S17. Absorption spectra of DMSO containing varied water content: (a) water content ranging from 0 to $1 \mathrm{vol} \%$; (b) water content ranging from 0 to $100 \mathrm{vol} \%$. The inset in (b) is corresponding absorption at $980 \mathrm{~nm}$ as a function of water content. 


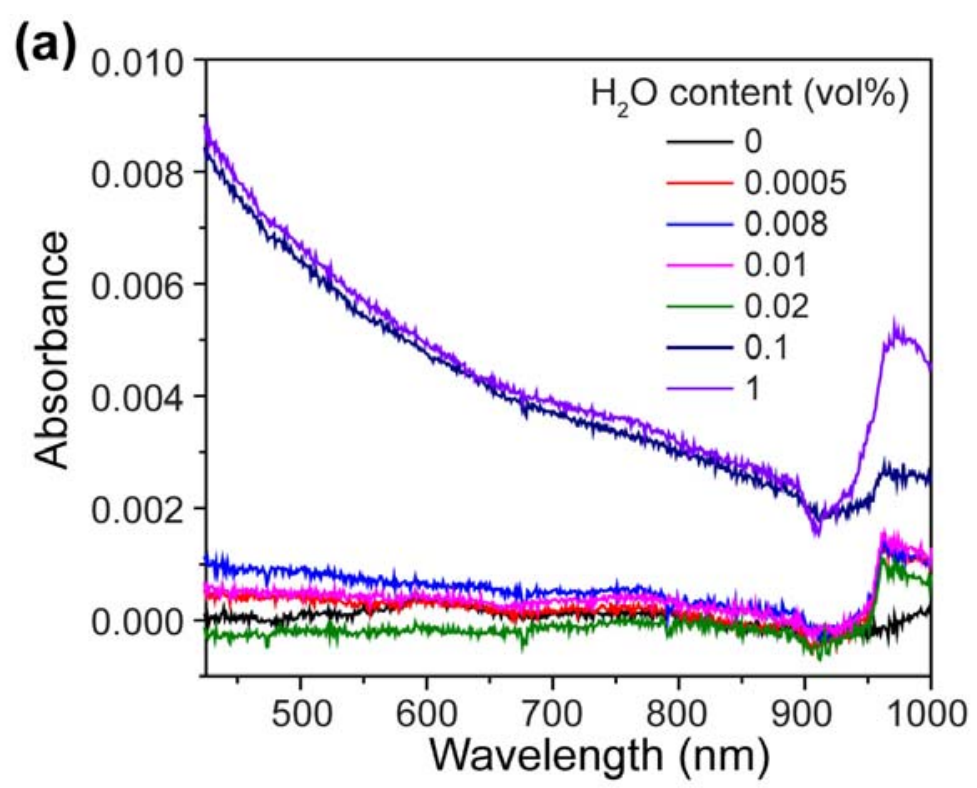

(b)

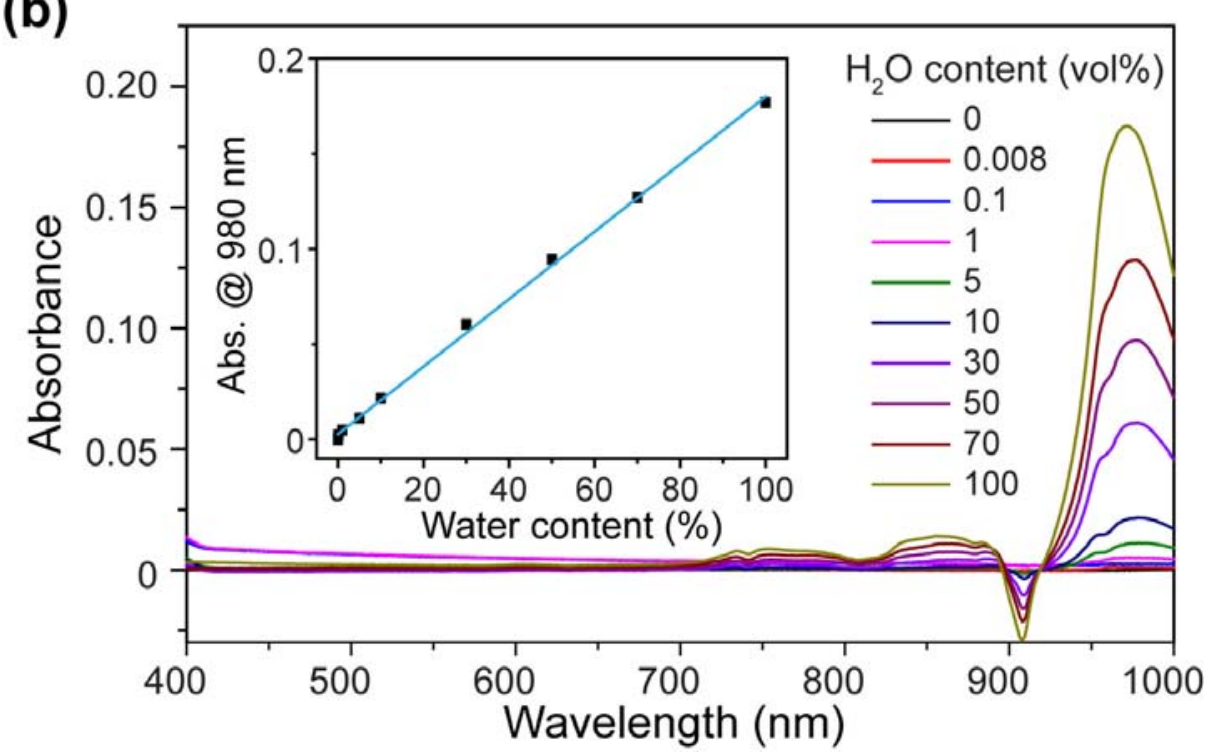

Figure S18. Absorption spectra of ethanol containing varied water content: (a) water content ranging from 0 to $1 \mathrm{vol} \%$; (b) water content ranging from 0 to $100 \mathrm{vol} \%$. The inset in (b) is corresponding absorption at $980 \mathrm{~nm}$ as a function of water content. 

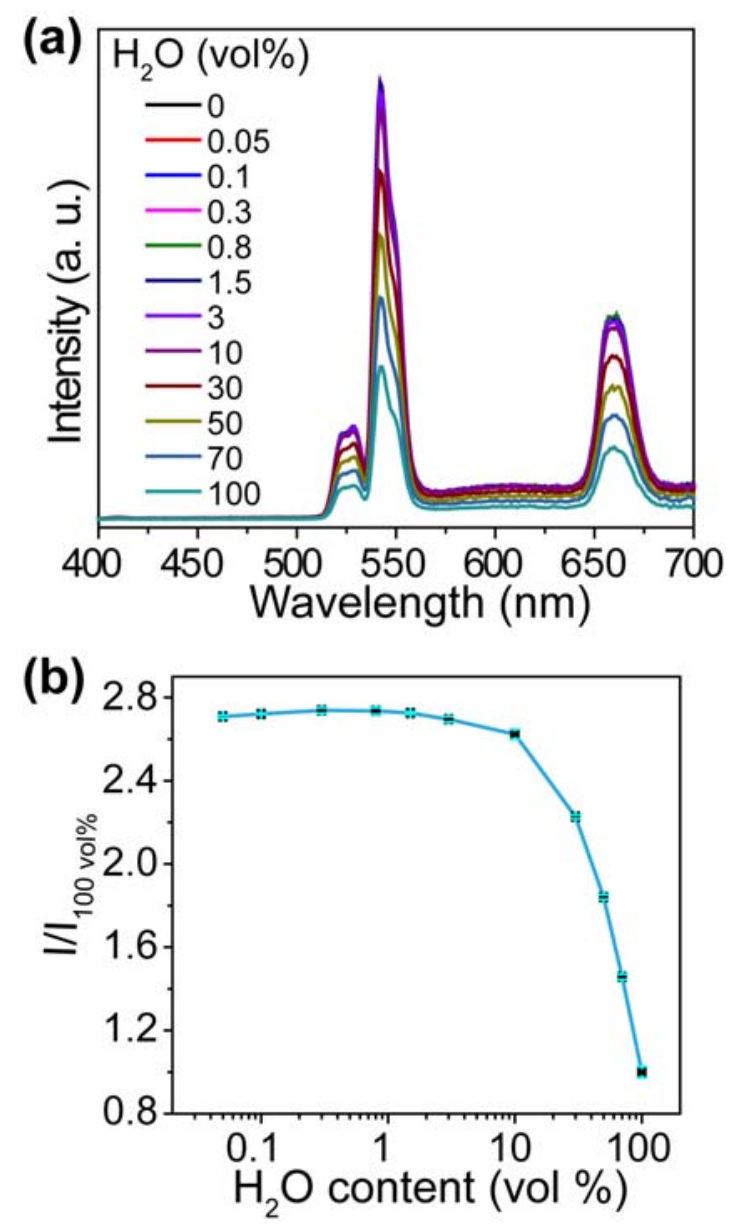

Figure S19. (a) Upconversion emission changes of $\mathrm{NaYF}_{4}: \mathrm{Yb} / \mathrm{Er} @ \mathrm{NaYF}_{4}$ core-shell nanoparticles as a function of $\mathrm{H}_{2} \mathrm{O}$ concentration (0-100 vol \%) in DMSO utilizing noncontact method. (b) Corresponding emission intensity dependence on $\mathrm{H}_{2} \mathrm{O}$ concentration (0.05-100 vol \%). Note that the emission intensity was obtained by integrating the emission from 400 to $700 \mathrm{~nm}$. The line serves as a guide to the eye and data are presented as the average from three measurements. 

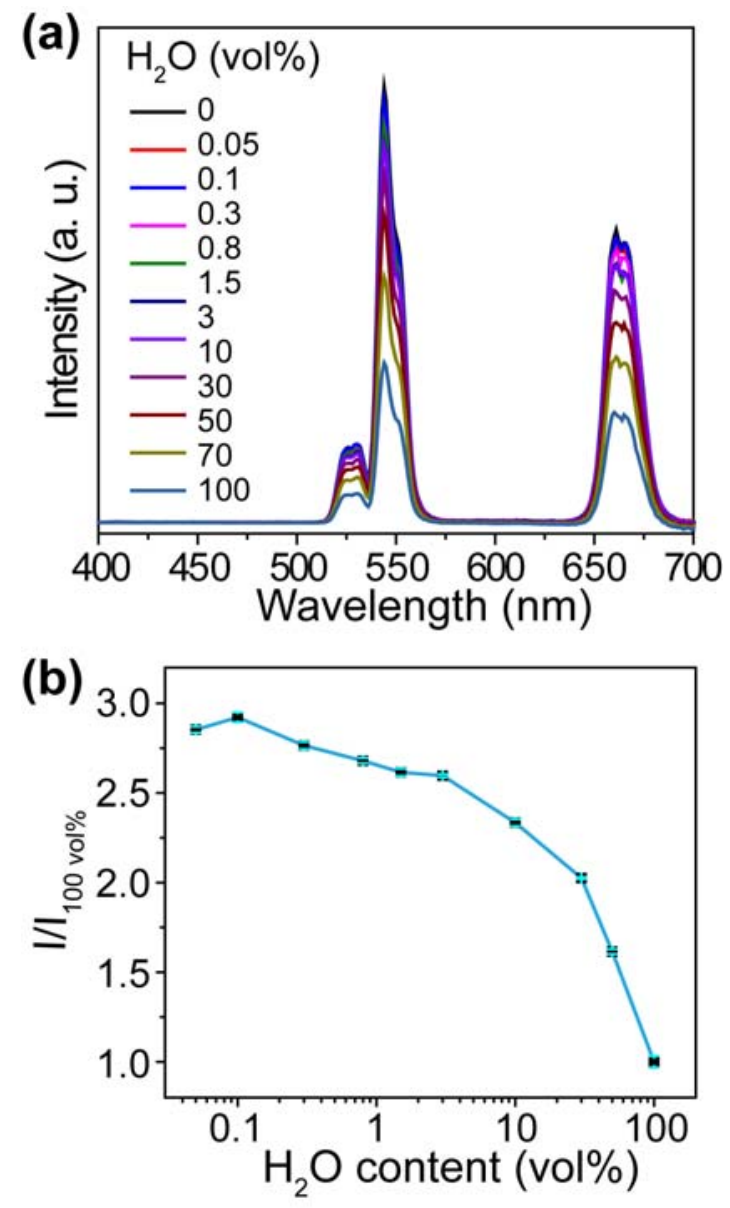

Figure S20. (a) Upconversion emission changes of $\mathrm{NaYF}_{4}: \mathrm{Yb} / \mathrm{Er} @ \mathrm{NaYF}_{4}$ core-shell nanoparticles as a function of $\mathrm{H}_{2} \mathrm{O}$ concentration (0-100 vol \%) in ethanol utilizing noncontact method. (b) Corresponding emission intensity dependence on $\mathrm{H}_{2} \mathrm{O}$ concentration $(0.05-100$ vol \%). Note that the emission intensity was obtained by integrating the emission from 400 to $700 \mathrm{~nm}$. The line serves as a guide to the eye and data are presented as the average from three measurements. 